\title{
Practice and Thinking about Building Technology Innovation Education
}

\author{
Yanyan Huang ${ }^{1, a}$, Xiaobiao Lv ${ }^{1, b}$, Yiquan Zou ${ }^{1, c}$ \\ ${ }^{1}$ School of Civil Engineering and Architecture, Hubei University of Technology, \\ Wuhan City, Hubei Province, China 430068 \\ ahuangyianyian@sina.com, blvxiaobiaohn@163.com, czyq124@126.com
}

Keywords: Building technology; Ecological construction; Learning community; Self-making

\begin{abstract}
The development of the situation has raised new requirements for the architectural designers, but traditional education about building technology is insufficient. The purposes of the adjustment of building technology course structure, implementation of interdisciplinary construction technology teaching and the introduction of cross-specialty graduation design with design institute pattern are to expand the connotation of building technology education and better cultivate students with characteristics.
\end{abstract}

\section{Introduction}

The development of the Construction industry situation has raised new requirements for the architectural designer, but in response to the training process of the professional architectural designers in the universities, it is hard to avoid some shortages, such as the emphasis on the artistic quality of architectural design but the oversight for the design's technicality as well as the disjointing of technology and design, especially there are few contents related to the ecological and sustainable development in building technology education. Therefore, it is especially important and urgent to expand the connotation of building technology education and the exploration of a set of building technology education mode with sustainability and openness and then to build a stress to the engineering characteristic of building technology education and to better cultivate students with characteristics.

Based on many years of teaching practice in School of Civil Engineering and Architecture, Hubei University of Technology, the author holds the view that the architectural specialty with characteristics should focus on building technology and engineering practice.

\section{Adjust the course structure of the building technology to strive for knowledge innovation}

In the twenty-first Century, the understanding of the field of architecture for green building has gone from the initial feasibility discussion to the current ecological consciousness and action. The series courses of the building technology mainly include architectural construction, architectural physics, building materials, construction equipment, construction mechanics, building CAD and other related curricula and designs. As for the teaching material and the teaching content, there are few contents related to the ecology, energy saving and sustainable development, and there are overlapping and duplication of related content. Therefore, the curriculum structure of the building technology should be adjusted to set up the related technology courses such as green building and ecological building, making the concept and the technology of the building field develop at the 
same pace.

Expand and integrate the content of the building technology series courses. The author participated in the programming revision in her own unit. As for what largely change, A General Outline of Building Technology (sixteen class hours)is opened as the basic compulsory course in the first semester of architecture specialty in order to make the students realize the importance of building technology from the beginning, and in the seventh semester A General Outline of Green Architecture (thirty-two class hours) is increased as an elective course to explain the important basic knowledge and theories of the green architecture to the students.

In order to promote the "reform" smoothly, we take Architecture Construction as the structural adjustment's pilot of building technology series courses, and creatively change Architecture Construction(volume 1 and 2) offered during the whole sophomore year into three modules, that is, "123", " 1 " means the basic structure, "2" means the decorative structure, respectively offered in the first and the second semester of the sophomore year, "3" means the special structure offered in the first semester of the senior year. Through this reform, not only the content of Architecture Construction is increased, but also the coordination between Architecture Construction and other technical courses is promoted.

Have a thorough knowledge of the architectural design and the building technology series courses and diversify the teaching model. As one of the major architectural courses, the building technology series courses are offered to enhance the engineering consciousness of students in the architecture specialty, which is inseparable from the architectural design. But for a long time, the architectural design and the building technology education has been disjointed, directly affecting the students' ability of engineering design.

The most effective way to solve this problem is to moderately have a thorough knowledge of the architectural design and the building technology series courses. In the author's unit, many teachers who teach the design courses are also engaged in the teaching of the building technology course. In order to make full use of this advantage, we use the "X+2" teaching model in the teaching of the design course in different grades. Specifically, " $X$ " means the integrated building design in each academic year, whole " 2 " means the 2 weeks' project design of the building technology. Each students' project work of different grades should accordingly meet the technical requirements, the teacher of the technical course should involve in the design guidance and evaluation at the certain stage. Even in the forth and the fifth grade, we give the teacher of the technical course priority to speak while the teacher of the design course assists.

\section{Carry out the building technology teaching of the interdisciplinary collaboration to achieve the synergy of production, study and research}

Architecture is a unique personality discipline among the engineering disciplines, involving aesthetics, environmental studies, physics, history, economics and management science and other fields, so it has the interdisciplinary property. A complete building design often requires the design steps such as construction, structure, water, electricity, heating and equipment to cooperate with each other. Form the development trend of modern architecture, the architectural function and shape are more and more complex and the involved field is more and more wide, which further needs the high coordination of every professional fields. At present, the traditional departmental teaching is difficult to adapt to the development of the situation and the requirements of the engineering development. Therefore, the interdisciplinary education of the building technology highlights as the 
requirements of the times.

Form the cross-specialty "learning community". The cross-specialty "learning community" is composed of students with different majors emphasizing the interaction in the learning process to complete the common learning task and promote its members to grow together. The students in the "learning community" include architecture, civil engineering, project management, interior design, urban planning and other professional students, and there are about ten students in every "learning community".

Therefore, we change the traditional method that there is one teacher for one course and have a group of teachers from different majors as a teaching team to teach one course. For example, in the course of Green Architecture, there are teachers from architecture, project management and building equipment majors teaching the course at different stages. We take the method of "going out and inviting in", that is, the school encourages teachers to go to the national famous architectural design institute for research study; at the same time the school also employs a group of local famous senior engineer as outside teachers to enrich the teaching form and expand the school teacher's visual field.

The cross-specialty graduation design from the design institute pattern of the school-enterprise cooperation. In order to effectively achieve the interdisciplinary cooperation of architectural technology teaching, from the beginning of 2011, we set the pilot project to build a team of graduation design and introduce the cross-specialty graduation design with design institute pattern. The specific practices include combining the graduates from all majors (architecture, civil engineering, project management and traffic engineering) to form many student design teams, and composing the guidance team for graduation design with teachers from different majors, the team formed by teachers and students jointly complete the comprehensive practical projects provided by enterprises according to the work mode of the design institute. According to the feedback of the employing unit, these graduates show good professional design ability and comprehensive coordination ability in the unit.

\section{Build the new experiment and teaching system of building technology education to highlight the cultivation of innovation ability}

Along with the development of information technology, the breakthrough of the discipline of architecture depends more and more on advanced experimental technology, and the professional education content of the architecture changes from the traditional static two-dimensional plane to the three dimension and four dimension dynamic, which not only needs a high level of experiment technology conditions to support, also needs an innovative experiment and teaching system with high quality to guarantee.

The "homemade" and "sustainable" laboratory built by both the students and the teachers. In the construction of the lab ,we apply for the building of the homemade laboratory, that is, the location, design, funding budget and construction of the laboratory are all finished by the teachers and the students, and the whole process lasts eight months and there are 10 teachers and more than 100 construction specialty students involving in the building. The laboratory has a total area of two hundred square meters, including the construction area of the building model(refer to Fig. 1), the showcase of the building materials and the decorative materials(refer to Fig. 2), the structure showcase and a small scale building with the sloping roof, and the building materials and the display materials are bought and collected by the students. This "homemade" construction let teachers and students experience how to combine architectural construction theory with practice and 
exercise the teachers' and students' practical ability.

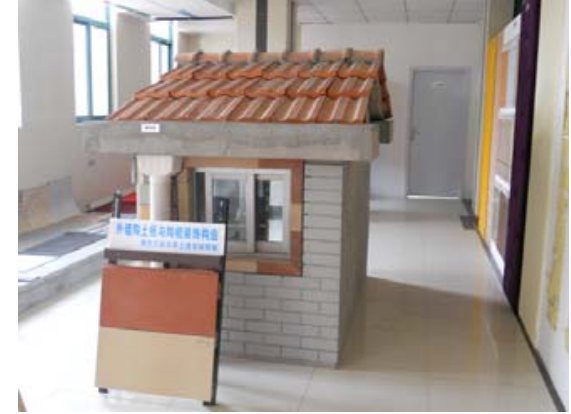

Fig. 1 Simulation model of slopping roof building

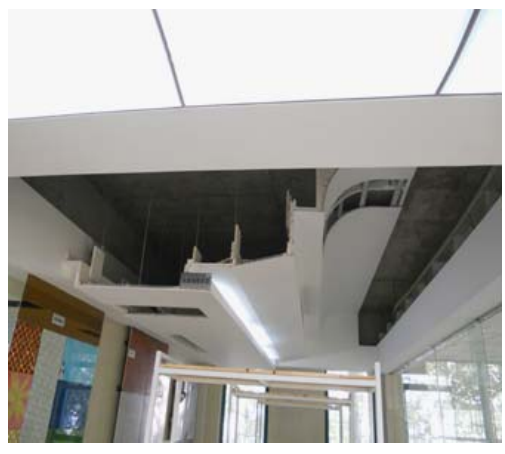

Fig. 2 Pilot site of hierarchy ceiling construction

Build the innovation system of the experimental teaching. The new experimental teaching system is designed according to the overall requirements of talent training highlighting the cultivation of the comprehensive quality, the practical ability and innovative thinking. The experimental and practical teaching system is built with the goal of serving the "professional series foundation course system" and "professional series expansive course system" to hierarchically combine with theoretical teaching in multiple modules and be relatively independent.

For example, one of the specific topic of building innovation experiments is taking use of the waste materials to design and build the grounds and the walls, asking students in groups to apply their knowledge to design various walls(refer to Fig. 3) and grounds(refer to Fig. 4), then build them. Students in the experiment will encounter many unforeseen circumstances and experimental conditions may also changes. Facts prove the experiments are helpful to cultivate the students' thinking ability and innovation ability, because there is space for free play and the students have greatly enthusiasm for the experiments.

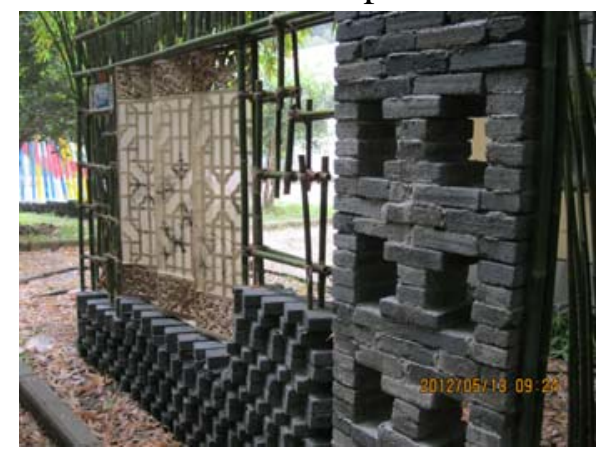

Fig. 3 Partition wall

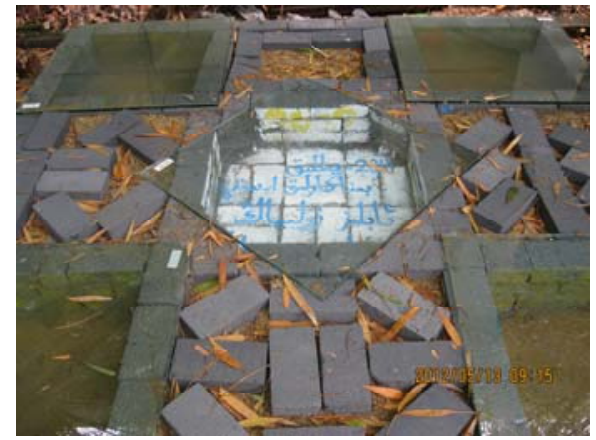

Fig. 4 Ground

\section{Conclusion}

Research and practice of the Building Technology Innovation Education is an important subject of cultivating innovative talents. It is a complex systemic project, which not only needs to straighten out the course structure, still needs to deal with the relationship with adjacent disciplines as well as the combination between theory and practice. How to maintain its own characteristics and to update timely meeting the need of the social developments will always be the exploratory goal of the teachers of the architectural specialty in future.

\section{References}

[1] Xiaobiao Lv, Yiquan Zou, Yanyan Huang: The 3D Coordinated Building Design Based on 
Building Information Modeling. Advances in Civil Engineering and Architecture(Part 7):6587-6591(2012)

[2] Yanyan Huang, Xiaobiao Lv: The Architectural Design Strategies of Low Carbon Economy. Journal of Hubei University of Technology,Vol.5(2011),p121

[3] Peng Yue, Xi Zhao: Study on the teaching method of the course of building construction technology under the new situation of teaching method. Journal of Architectural Education, Vol.1(2009),p126

[4] Qiliang Yu, Yongsheng Chen: Architectural Design Technology and Curriculum Reform reconfiguration scheme. China Construction Education, Vol.3(2010)2010,p58

[5] Juan Fu, Dawei Xiao: Discussion on teaching method based on the laws of architecture students. Huazhong architecture, Vol.10(2010),p185

[6] Zhenhe Fan: Construction of Students' comprehensive ability base on teaching reform of building construction practice, Vol.4(2007),p137 